NEWS

\title{
Celebrity genomes alarm researchers
}

Genome researchers are questioning the plans of some of their number to stage high-profile releases of their very own genome sequences.

Tension over the issue surfaced this month at the annual genomics meeting at Cold Spring Harbor Laboratory in New York. There, some researchers expressed concerns that sequencing prominent scientists first will make personal genomics look like a tool for the rich and privileged.

At the meeting, Michael Egholm, a vice-president at 454 Life Sciences, a sequencing technology company in Branford, Connecticut, stood by a poster describing his company's effort to sequence the genome of genetics pioneer James Watson. The company claims this is the first sequence of an individual human genome, and that it took three months and cost about $\$ 1$ million. "So, is this the next space tourism?" joked a scientist inspecting the poster.

Egholm winced at the implication that his company's plan is a vanity project for the wealthy. "What really matters is the next 100 genomes," he responded, carefully.

The exchange reflects tension between geneticists over whether sequencing scientists and celebrities is the best way to begin the long-promised era of personalized medicine. Watson and a handful of other famous people will be the first to see their complete genome sequences - and some scientists are uncomfortable with that.

"If all the sequences obtained over the next year or two are done on scientists with strong financial positions, that will send a message quite contrary to what the genome project aimed to achieve," says Francis Collins, head of the US National Human Genome Research Institute (NHGRI) in Bethesda, Maryland.

The sequencing of individual human of his genome will be described in an upcoming paper in the journal PLoS Biology.

Next up will probably be sequencing guru George Church of Harvard University, who is one of the first ten volunteers for his privately funded Personal Genome Project. Then there is the Archon X Prize in Genomics - a \$10-million cash award for the first team to sequence 100 genomes in 10 days - for which Venter is
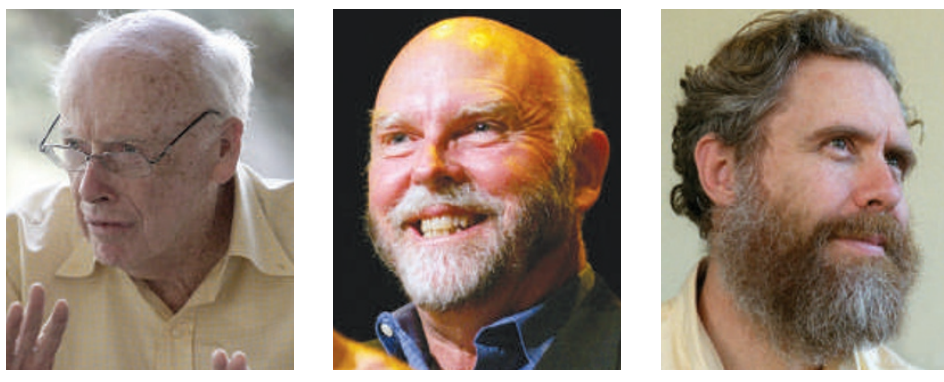
co-chair of the scientific advican claim a \$1-million bonus by sequencing a list of 100 individuals, including people nominated by disease advocacy groups, and celebrities such as television journalist Larry King, cosmologist Stephen Hawking, Google co-founder Larry Page, Microsoft co-founder Paul Allen and former junk-bond trader Michael Milken.

genomes has long been a central goal of genomics. In 2001, the Human Genome Project produced a reference genome from the DNA of many different individuals. As with that project, attempts to sequence individual genomes are culminating in a race to finish first. On 31 May, 454 is expected to join scientists at Baylor College of Medicine in Houston, Texas, to present Watson with a copy of his genome.

But genomics pioneer Craig Venter claims he has already sequenced and assembled his own genome and submitted it to the publicly funded database GenBank. He says an analysis
The scramble has some researchers wondering whether the public will see personal genomics as an activity for the benefit of humanity. "I'd hate the availability of singlegenome sequencing to be based purely on money and fame," says Michael Ashburner, a geneticist at the University of Cambridge, UK. "Just doing famous or very rich people is bloody tacky, actually."

"This is almost like recreational genomics, or the molecular equivalent of a whole-body scan, for those who have boundless curiosity and cash," says Kathy Hudson, director of Johns

\section{Plans forge ahead for better weather monitoring}

Meteorologists are planning a coordinated global drive to recalibrate space-based measurements of the weather. The weather scientists are confident that better calibration will result in better data - and a fuller picture of global climate change.

Meeting last week in Geneva, the World Meteorological Organization announced plans for a Global Spacebased Inter-Calibration System (GSICS). The initiative will ask national satellite agencies to take steps to ensure better comparability of satellite measurements made by different instruments and satellites, and to tie these measurements to absolute references.

"As the requirement for monitoring global climate becomes clearer, there is need for more accurate measurements," says Don Hinsman, director of the World Meteorological Organization's space programme. "To permit early detection of climate change, it is vital that satellite instrument calibration is of the highest quality, and that a capability exists to cross-calibrate satellite sensors."

Remote sensing by some
30 satellites forms the backbone of global weather and climate monitoring today. Such measurements are vital because reliable ground-based observations are available for only about a quarter of Earth's surface. Continuous measurement of oceans, deserts and other remote and sparsely populated areas can come only from space.

But such measurements are prone to error, with problems arising from instrument degradation over time, small deviations of the satellites from their planned orbits, and faults in the algorithms used to process raw numerical data into meaningful geophysical information.

Flawed satellite data have caused disagreements between scientists in the past over such matters as temperature trends in the troposphere'. One radiometer onboard a US National Oceanic and Atmospheric Administration satellite - the only instrument to measure temperature in the stratosphere before 1998 - is thought to have transmitted grossly biased temperature measurements since 1979 (ref. 2). 


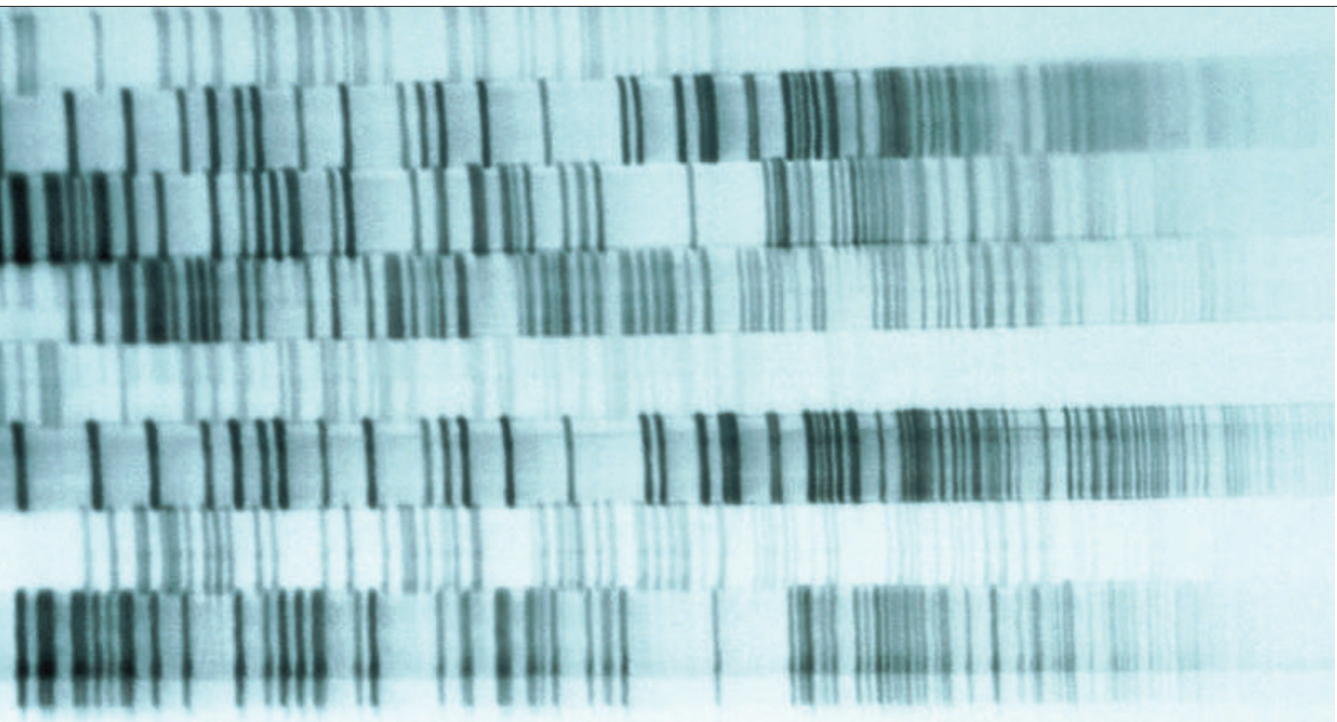

Some geneticists worry that sequencing the rich and famous is a misuse of genomics.

Hopkins University's Genetics and Public Policy Centre in Washington DC. "It will be sort of a sad statement if that's what we end up getting out of the Human Genome Project."

Scientists such as Venter counter that sequencing themselves first will defuse public anxiety about the possible misuse of genomic data by insurers, employers and others. The institutional review board that approved Church's project, for instance, said that only people with a master's degree in genetics, or the equivalent, should be allowed to volunteer, to ensure that they understand the implications.

Venter says he is creating a database where sequenced individuals can put genetic and personal information, such as medical records. $\mathrm{He}$ says he will deposit his own clinical information, possibly when his book A Life Decoded: My Genome, My Life is published in October.

"I think it would be wrong to take ten 'average' people and try to convince them it's all right for them to have their genetic code and life histories exposed on the Internet if people in a leadership position are not willing to do that," Venter says.

But it's not clear that all of the genome pioneers are acting altruistically. Watson said at the Cold Spring Harbor meeting on 10 May that he has not asked either of his grown sons for permission to publish his genome sequence, which 454 has said will be publicly posted in some form. That has raised questions about the responsibility of sequenced individuals to

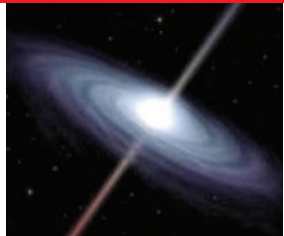

HOW TO SURVIVE IN A

BLACK HOLE

There's no escape, but how can you maximize your remaining time?

www.nature.com/news family members who share their DNA.

"This will be a challenging question, because if you're planning to put this information in a truly open database, there are issues of risk not just to you, but to your relatives," Collins says. "Jim clearly felt those risks were not such as to cause him to take action on them."

Watson knows that he and other individuals will not learn much of use from their own genomes - at least, not yet. Scientists are still learning to interpret genomic data, and have yet to unravel the genetic signatures of most diseases. There are some exceptions - Watson has asked 454 not to reveal the status of his gene for apolipoprotein E, because it is associated with Alzheimer's disease. But for the most part, personal genomes will not become useful until hundreds or thousands of individual genomes have been analysed.

The NHGRI is now planning to sequence about 100 individual genomes at its three publicly funded sequencing centres over the next couple of years. Collins says the institute will ask for scientific advice on who should be sequenced first. One question is what pool of sequenced individuals will yield the most useful information.

For instance, it might be possible to discover the basis of a rare genetic disease by sequencing many families affected by it. Scientists could also learn much from cancer patients or people who have already been studied in the International HapMap Project, a publicly funded effort to look at human genetic variation.

"We would want these to be chosen in such a way that you could get maximum information out of them, and there are various opinions about what that would mean," Collins says. Erika Check
Even small temperature discrepancies, if undiscovered, can seriously disrupt the study of climate trends. "Inter-calibration has to be almost perfect if we want to look at climate trends otherwise the bias will be stronger than the signal you want to address," says Jean-Noël Thépaut, who heads the satellite section at the European Centre for Medium-Range Weather Forecasts in Reading, UK.

The onboard calibration of instruments is costly and technically challenging, and provision for it has been incorporated only into new satellites. But just as important is the occasional lack of consistency between data collected from different satellite missions.

"The development of new sensor technology is progressing much faster than our capability to validate data," explains Gerhard Adrian,

"To permit early detection of climate change, it is vital that satellite instrument calibration is of the highest quality."

head of research at the German Weather Service in Wiesbaden.

The GSICS will make use of the exceptionally well-calibrated sensors onboard the latest generation of European and US meteorological satellites - such as Europe's MetOp-A satellite, which became operational last week - to validate data from older instruments.

"Cross-calibration is very much in our own interest," says Johannes Schmetz, head of the meteorology division at EUMETSAT, the European Organisation for the Exploitation of Meteorological Satellites in Darmstadt, Germany, and a member of a panel that will run the GSICS. "Ideally, what we would like to have is an operational system that could precisely define, and correct for, any orbital and instrumental biases in real time."

Reprocessing recently archived data using improved algorithms is also part of the plan. At EUMETSAT, robots can now do this quite quickly. Cumbersome manual 'data archaeology' is required only for old data sets stored on unwieldy magnetic tape.

Satellite data are becoming ever more abundant. At the European weather centre in Reading, for example, more than 5 million data points are processed every day, with the volume of data likely to triple in the next few years.

Quirin Schiermeier

1. Mears, C. A. \& Wentz, F. J. Science 309, 1548-1551 (2005)

2. Nash, J. \& Edge, P. R. Adv. Space Res. 7 333-341(1989) 